\title{
Lamarckian evolution explains human brain evolution and psychiatric disorders
}

\author{
Guy Barry* \\ Neuroscience Division, Garvan Institute of Medical Research, Darlinghurst, NSW, Australia \\ ${ }^{*}$ Correspondence: g.barry@garvan.org.au \\ Edited by: \\ Karol Osipowicz, Jefferson Neuroscience Hospital, USA \\ Reviewed by: \\ Ilanit T. Young, Veterans Medical Research Foundation, USA
}

Keywords: Lamarckian inheritance, pangenesis, psychiatric disease, vesicle, small non-coding RNA, de novo mutations

The current model of evolution, dominated by the Darwinian theory, is becoming increasingly improbable as a complete explanation of the forces driving human brain evolution. An underappreciated concept exists, proposed more than two centuries ago by Jean-Baptiste Lamarck, whereby somatic cells pass experience-dependent, and ultimately adaptive, information to subsequent generations. However, since no mechanism could be demonstrated, this theory was gradually displaced in favor of the more intellectually lenient modern evolutionary theory where powerful selection pressures result in the inheritance of beneficial genetic variations, randomly generated in the germline, that bestow greater fitness to subsequent generations. Recent evidence from studies, including psychiatric disease, suggests a mechanism whereby organisms constantly adapt to the environment and that this crucial information is passed to their offspring, rather than relying on a germline-independent and indiscriminate mechanism that takes no cues from the outside milieu. I propose that a combination of Darwin's hypothesis on pangenesis, coupled with Lamarckian somatic cellderived epigenetic modifications and de novo RNA and DNA mutations, is the dominant mechanism of current cognitive evolution.

\section{EVOLUTION OF HIGHER-ORDER COGNITION}

The human brain has remarkably tripled in size over the past five million years since the split from our nearest relative, the chimpanzee (Bradbury, 2005). The increased size of the neocortex, especially the prefrontal cortex (Balsters et al., 2010), is thought to provide a substrate for some of the enhanced cognitive abilities observed in humans (Kolb et al., 2012). Although some neural proteincoding genes have undergone some positive selection during this time (Dorus et al., 2004; Vallender et al., 2008), it is the expansion in the dynamically regulated non-protein-coding regions of the genome that display the most striking parallels with human brain progression (Taft et al., 2007). We have hypothesized that the noncoding repertoire, including various repeat elements, and RNA editing, have been the driving force for the increased flexibility of the brain resulting in stimulus-dependent adaptation ultimately leading to evolved higher-order cognition and, upon dysregulation, associated psychiatric disease (Barry and Mattick, 2012). However, this does depend on a mechanism allowing the transgenerational transmission of adaptive neuronal changes from the somatic cells of the brain. It is likely that both coding (proteins) and non-coding (regulatory effectors) regions of the genome undergo adaptive change to external stimuli and that these changes will be reflected in the transcriptomic output of the specific cell. But would experience-dependent de novo changes be beneficial to the evolution of an organism and, if so, how are they transmitted to the germline?

\section{De novo MUTATIONS UNDERLIE PSYCHIATRIC DISORDERS}

Psychiatric disorders such as autism, schizophrenia, and intellectual disability offer valuable insight into current evolutionary mechanisms. The recent advent of next generation sequencing, especially where parents and affected and non-affected siblings were sequenced to detect de novo mutations, has allowed an unprecedented view of whole genome transcriptomics in human brain evolution (Johnson et al., 2009). Strikingly, although the prevalence of individual de novo mutations in autism is extremely low, the mutations seem to cluster to specific genetic pathways (Neale et al., 2012; O'Roak et al., 2012a,b). Copy number variations arising from de novo mutations also play a significant role in sporadic cases of autism (Itsara et al., 2010; Sanders et al., 2011; Devlin and Scherer, 2012) and schizophrenia (Rees et al., 2012). Furthermore, intellectual disability is strongly associated with de novo mutations (Girirajan et al., 2011; de Ligt et al., 2012; Rauch et al., 2012; Veltman and Brunner, 2012) reinforcing these mechanisms as causative in cognitive disorders. As more studies are performed on patients with psychiatric disorders it is becoming apparent that there is a significant overlap in gene pathways affected by de novo mutations (Gilman et al., 2012). It must be noted that this process is in all likelihood not entirely deleterious because if mutations arose that were neutral or advantageous they would not be studied to nearly the same degree as those associated with negative effects. Future studies investigating higher cognitive abilities in "normal" subjects would be of great interest to the field. I believe that this reveals the current evolutionary phase of stimulusdependent adaptation to enhance cognition. Overall, these data provide strong evidence that brain evolution is, at least partly, not random, but instead driven by targeted de novo genetic mutations and inherently assumes a method of somatic transmission due to high heritability rates (Yu et al., 2013).

The increased risk of psychiatric diseases, such as autism and 
schizophrenia, with increasing paternal age (Kong et al., 2012) suggests that accumulating de novo mutations in the brain are heritable and predominantly arise from sperm. The age-related decrease in sperm quality does not seem to be an adequate explanation for this as the mutations cluster non-randomly in specific genetic pathways. Maternally transmitted epigenetic inheritance undoubtedly occurs during maternal exposure to adverse conditions, such as stress and obesity, during pregnancy (Dunn et al., 2011; Matthews and Phillips, 2012) and in some cases of autism (Cook et al., 1997; Noor et al., 2010). However, due to the limited number of eggs contained in ovaries, and therefore, the limited scope for non-stress related experimentation, it would seem reasonable that the almost limitless number of sperm would be better suited to testing the consequences of directed de novo mutations. Moreover, epigenetic effects that transfer from the sperm is more acceptable since the possibility that the eggs themselves are exposed to the stress are excluded.

\section{TRANSGENERATIONAL EPIGENETIC INHERITANCE}

The field of epigenetics has recently revealed evidence of experiencedependent transgenerational inheritance. The modern evolutionary theory proposes that evolution occurs through a combination of Mendelian genetics and Darwin's theory of natural selection (Kutschera and Niklas, 2004). However, examples contradicting this theory have emerged such as the contribution of modifiable epigenetic processes that do not disturb DNA sequence (Danchin et al., 2011). Epigenetic mechanisms involved in inheritance include DNA methylation, histone modifications, and small non-coding RNA (sncRNA)-driven mechanisms, e.g., small interfering RNA (siRNA), piwiinteracting RNA (piRNA), and microRNA (miRNA). Epigenetic alterations contribute to transgenerational inheritance in plants, such as during adaptive plasticity in response to pathogenic invasion (Holeski et al., 2012). Likewise, analogous epigenetic mechanisms transmit potentially somatic experience-dependent information across generations in $C$. elegans (Rechavi et al., 2011; Ashe et al., 2012).
Although the demonstration of specific sncRNA-dependent mechanisms involved in transgenerational inheritance are scarce in mammals it is clear that transgenerational inheritance does indeed occur in mammals (Rassoulzadegan et al., 2006; Daxinger and Whitelaw, 2012; SaavedraRodriguez and Feig, 2013; Vassoler et al., 2013), including in the brain (Bohacek et al., 2013). Furthermore, unlike plants, metazoans possess an extra class of small RNAs, piRNAs that, although initially thought to be germ cell-specific, are present in the brain (Rajasethupathy et al., 2012) and have been demonstrated to be involved in transgenerational inheritance (Ashe et al., 2012; Grentzinger et al., 2012). The transfer of somatic information from organs, like the brain, to the testis would require that separate organs are capable of the same processes (to ensure equivalent transcriptional regulation) as is the case for sncRNAs as these mechanisms are present in the germline (Saxe and Lin, 2011; Ashe et al., 2012; Buckley et al., 2012) and in the brain (Qureshi and Mehler, 2012).

Although not yet demonstrated, sncRNAs would additionally require the ability to induce DNA changes, either directly or indirectly, to influence inheritance patterns of de novo mutations in psychiatric disease uncovered through exome sequencing (as discussed above). At least two mechanisms are possible; First, sncRNAs are able to induce a DNA change through regulating DNA repair (Francia et al., 2012; Chowdhury et al., 2013) and, second, determining site-selectivity for generic DNA editing enzymes, such as the APOBEC family (Smith et al., 2012), some members of which are recently implicated in psychiatric disease (Dong et al., 2012). It is also been suggested that these two mechanisms function together in DNA recoding to enhance cognitive evolution (Mattick and Mehler, 2008).

\section{POSSIBLE MECHANISM OF TRANSMISSION OF LAMARCKIAN INHERITANCE}

The Lamarckian theory of inheritance has historically been rejected due to a lack of a confirmed mechanism. However, I believe that long-range RNA-mediated information transmission is best suited to fill this role. In plants, regulatory information, conveyed through stimulusdependent transcription of small noncoding RNAs (Sunkar and Zhu, 2004; Mallory and Vaucheret, 2006) and their long-distance transport throughout the plant (Yoo et al., 2004; Chuck and O'Connor, 2010), has been harnessed for the transmission of adaptive somatic cell responses. The utilization of RNA as a method of communication between cells is present in all organisms, including humans, where regulatory information is passed locally and systemically within vesicles (Thery et al., 2002; Fevrier and Raposo, 2004; Ratajczak et al., 2006; Dinger et al., 2008; Muralidharan-Chari et al., 2010). Extracellular vesicles have been shown to pass through the bloodbrain barrier, and are similarly likely to pass through the blood-testis barrier, and may be of significant clinical relevance for disease biomarkers and therapeutic delivery due to this unique endogenous ability (van der Pol et al., 2012). Indeed, "biomarkers" may exist in the bloodstream due to the active process of longrange communication between somatic cells, and somatic cells and the germline. Recent reports suggest blood biomarkers can be used to detect psychiatric disorders such as schizophrenia (Schwarz et al., 2012), autism (Momeni et al., 2012), and may predict suicidality (Le-Niculescu et al., 2013), possibly reflecting a snapshot of real-time cellular transcription that would incorporate disease-associated sporadic de novo mutations.

Charles Darwin proposed that there existed particles of inheritance, called "gemmules" or "pangenes," that carried information of inheritance to the sexual elements and that these particles may be modifiable by the environment (Darwin, 1868). I propose that these particles are in fact vesicles, released by many tissues into the bloodstream (van der Pol et al., 2012) and that they provide an attractive means of transmission for RNA-mediated somatic cell-derived regulatory information to the germline. Vesicles contain mostly sncRNA (Lasser et al., 2012), especially miRNA (GuduricFuchs et al., 2012) that may be differentially expressed in psychiatric disease (Banigan et al., 2013). Vesicles have also been demonstrated to relay RNA-coded information between neighboring neural 
cells (Fruhbeis et al., 2012) but definitive evidence for long-range RNA communication in mammalian systems has not yet been produced.

Recent ENCODE data reveal that testes show the highest quantity of transcription in the body (Howald et al., 2012) and, I postulate, that this may reflect the overall transcription from all other body regions. Brain tissue shows the second-highest rate of transcription and all other tissues are by a large extent less. I further suggest that this high level of transcription in the brain reflects the current state of evolution, where the human brain is undergoing extraordinary accelerated environment- and stimulusdependent adaptive evolution (as discussed above) and that this information is transferred to the testes for inheritance. Other tissues are concomitantly undergoing adaptive responses, albeit at normally lower levels, and that this information is also routed to the testes resulting in a higher overall rate of transcription in the testes compared with brain.

\section{CONCLUDING REMARKS AND FUTURE DIRECTIONS}

I propose that the human brain is undergoing an evolutionary explosion, with non-coding RNA-mediated mechanisms (allowing extraordinary adaptive plasticity) and somatic cell-derived, Lamarckiantype inheritance, driving this process. The prevailing hypothesis that brain evolution, or in fact any adaptive form of transgenerational inheritance, is independently controlled solely by a Darwinian method of random mutations and epigenetic modifications in the germline is highly unlikely as specific responses to many types of stressors, from plants through to humans, are robustly transmitted to subsequent generations (Rassoulzadegan et al., 2006; Rechavi et al., 2011; Ashe et al., 2012; Daxinger and Whitelaw, 2012; Holeski et al., 2012; Bohacek et al., 2013; SaavedraRodriguez and Feig, 2013; Vassoler et al., 2013).

There is little doubt that in the near future a mechanism of Lamarckian inheritance, possibly mediated by small regulatory RNA-containing vesicles, will be uncovered. However, before the wider scientific community accepts this hypothesis, it will be crucial to show vesicle transport, together with RNA cargo, between brain and testis, and specific stimulus-driven transcription in somatic cells reflected in the germline and subsequent inherited DNA and/or epigenetic modifications.

Darwin did not discard Lamarck's ideas on evolutionary mechanisms and was open to the idea of pangenesis where "gemmules" or "pangenes" would transmit somatic information to the germline. I believe that these exist as vesicles in the blood and that Lamarck's hypothesis on somatic inheritance coupled with Darwin's mechanism of pangenesis will be established as a more complete model of forces driving human brain evolution.

\section{REFERENCES}

Ashe, A., Sapetschnig, A., Weick, E. M., Mitchell, J., Bagijn, M. P., Cording, A. C., et al. (2012). piRNAs can trigger a multigenerational epigenetic memory in the germline of $C$. elegans. Cell 150, 88-99. doi: 10.1016/j.cell.2012.06.018

Balsters, J. H., Cussans, E., Diedrichsen, J., Phillips, K. A., Preuss, T. M., Rilling, J. K., et al. (2010). Evolution of the cerebellar cortex: the selective expansion of prefrontal-projecting cerebellar lobules. Neuroimage 49, 2045-2052. doi: 10.1016/j.neuroimage.2009.10.045

Banigan, M. G., Kao, P. F., Kozubek, J. A., Winslow, A. R., Medina, J., Costa, J., et al. (2013). Differential expression of exosomal microRNAs in prefrontal cortices of schizophrenia and bipolar disorder patients. PLoS ONE 8:e48814. doi: 10.1371/journal.pone.0048814

Barry, G., and Mattick, J. S. (2012). The role of regulatory RNA in cognitive evolution. Trends Cogn. Sci. 16, 497-503. doi: 10.1016/j.tics.2012.08.007

Bohacek, J., Gapp, K., Saab, B. J., and Mansuy, I. M. (2013). Transgenerational epigenetic effects on brain functions. Biol. Psychiatry 73, 313-320. doi: 10.1016/j.biopsych.2012.08.019

Bradbury, J. (2005). Molecular insights into human brain evolution. PLoS Biol. 3:e50. doi: 10.1371/journal.pbio.0030050

Buckley, B. A., Burkhart, K. B., Gu, S. G., Spracklin, G., Kershner, A., Fritz, H., et al. (2012). A nuclear Argonaute promotes multigenerational epigenetic inheritance and germline immortality. Nature 489, 447-451. doi: 10.1038/nature11352

Chowdhury, D., Choi, Y. E., and Brault, M. E. (2013). Charity begins at home: non-coding RNA functions in DNA repair. Nat. Rev. Mol. Cell Biol. 14, 181-189. doi: 10.1038/nrm3523

Chuck, G., and O'Connor, D. (2010). Small RNAs going the distance during plant development. Curr. Opin. Plant Biol. 13, 40-45. doi: 10.1016/j.pbi.2009.08.006

Cook, E. H. Jr., Lindgren, V., Leventhal, B. L., Courchesne, R., Lincoln, A., Shulman, C., et al. (1997). Autism or atypical autism in maternally but not paternally derived proximal $15 \mathrm{q}$ duplication. Am. J. Hum. Genet. 60, 928-934.

Danchin, E., Charmantier, A., Champagne, F. A., Mesoudi, A., Pujol, B., and Blanchet, S. (2011).
Beyond DNA: integrating inclusive inheritance into an extended theory of evolution. Nat. Rev. Genet. 12, 475-486. doi: 10.1038/nrg3028

Darwin, C. (1868). The Variation of Animals and Plants Under Domestication. London, John Murray.

Daxinger, L., and Whitelaw, E. (2012). Understanding transgenerational epigenetic inheritance via the gametes in mammals. Nat. Rev. Genet. 13, 153-162. doi: 10.1038/nrg3188

de Ligt, J., Willemsen, M. H., van Bon, B. W., Kleefstra, T., Yntema, H. G., Kroes, T., et al. (2012). Diagnostic exome sequencing in persons with severe intellectual disability. N.Engl. J. Med. 367, 1921-1929. doi: 10.1056/NEJMoa1206524

Devlin, B., and Scherer, S. W. (2012). Genetic architecture in autism spectrum disorder. Curr. Opin. Genet. Dev. 22, 229-237. doi: 10.1016/j.gde.2012.03.002

Dinger, M. E., Mercer, T. R., and Mattick, J. S. (2008). RNAs as extracellular signaling molecules. J. Mol. Endocrinol. 40, 151-159. doi: 10.1677/JME-070160

Dong, E., Gavin, D. P., Chen, Y., and Davis, J. (2012). Upregulation of TET1 and downregulation of APOBEC3A and APOBEC3C in the parietal cortex of psychotic patients. Transl. Psychiatry 2, e159. doi: $10.1038 /$ tp. 2012.86

Dorus, S., Vallender, E. J., Evans, P. D., Anderson, J. R., Gilbert, S. L., Mahowald, M., et al. (2004) Accelerated evolution of nervous system genes in the origin of Homo sapiens. Cell 119, 1027-1040. doi: 10.1016/j.cell.2004.11.040

Dunn, G. A., Morgan, C. P., and Bale, T. L. (2011). Sex-specificity in transgenerational epigenetic programming. Horm. Behav. 59, 290-295. doi: 10.1016/j.yhbeh.2010.05.004

Fevrier, B., and Raposo, G. (2004). Exosomes: endosomal-derived vesicles shipping extracellular messages. Curr. Opin. Cell Biol. 16, 415-421. doi: 10.1016/j.ceb.2004.06.003

Francia, S., Michelini, F., Saxena, A., Tang, D., de Hoon, M., Anelli, V., et al. (2012). Site-specific DICER and DROSHA RNA products control the DNA-damage response. Nature 488, 231-235. doi: 10.1038/nature11179

Fruhbeis, C., Frohlich, D., and Kramer-Albers, E. M. (2012). Emerging roles of exosomes in neuronglia communication. Front. Physiol. 3:119. doi: 10.3389/fphys.2012.00119

Gilman, S. R., Chang, J., Xu, B., Bawa, T. S., Gogos, J. A., Karayiorgou, M., et al. (2012). Diverse types of genetic variation converge on functional gene networks involved in schizophrenia. Nat. Neurosci. 15, 1723-1728. doi: 10.1038/nn.3261

Girirajan, S., Brkanac, Z., Coe, B. P., Baker, C., Vives, L., Vu, T. H., et al. (2011). Relative burden of large CNVs on a range of neurodevelopmental phenotypes. PLoS Genet. 7:e1002334. doi: 10.1371/journal.pgen.1002334

Grentzinger, T., Armenise, C., Brun, C., Mugat, B., Serrano, V., Pelisson, A., et al. (2012). piRNAmediated transgenerational inheritance of an acquired trait. Genome Res. 22, 1877-1888. doi: 10.1101/gr.136614.111

Guduric-Fuchs, J., O'Connor, A., Camp, B., O’Neill, C. L., Medina, R. J., and Simpson, D. A. (2012). Selective extracellular vesiclemediated export of an overlapping set of 
microRNAs from multiple cell types. BMC Genomics 13:357. doi: 10.1186/1471-216413-357

Holeski, L. M., Jander, G., and Agrawal, A. A. (2012). Transgenerational defense induction and epigenetic inheritance in plants. Trends Ecol. Evol. 27, 618-626. doi: 10.1016/j.tree.2012.07.011

Howald, C., Tanzer, A., Chrast, J., Kokocinski, F., Derrien, T., Walters, N., et al. (2012). Combining RT-PCR-seq and RNA-seq to catalog all genic elements encoded in the human genome. Genome Res. 22, 1698-1710. doi: 10.1101/gr.134478.111

Itsara, A., Wu, H., Smith, J. D., Nickerson, D. A., Romieu, I., London, S. J., et al. (2010). De novo rates and selection of large copy number variation. Genome Res. 20, 1469-1481. doi: 10.1101/gr.107680.110

Johnson, M. B., Kawasawa, Y. I., Mason, C. E., Krsnik, Z., Coppola, G., Bogdanovic, D., et al. (2009). Functional and evolutionary insights into human brain development through global transcriptome analysis. Neuron 62, 494-509. doi: 10.1016/j.neuron.2009.03.027

Kolb, B., Mychasiuk, R., Muhammad, A., Li, Y., Frost, D. O., and Gibb, R. (2012). Experience and the developing prefrontal cortex. Proc. Natl. Acad. Sci. U.S.A. 109(Suppl. 2), 17186-17193. doi: 10.1073/pnas.1121251109

Kong, A., Frigge, M. L., Masson, G., Besenbacher, S., Sulem, P., Magnusson, G., et al. (2012). Rate of de novo mutations and the importance of father's age to disease risk. Nature 488, 471-475. doi: 10.1038/nature11396

Kutschera, U., and Niklas, K. J. (2004). The modern theory of biological evolution: an expanded synthesis. Naturwissenschaften 91, 255-276. doi: 10.1007/s00114-004-0515-y

Lasser, C., Eldh, M., and Lotvall, J. (2012). Isolation and characterization of RNA-containing exosomes. J. Vis. Exp. e3037. doi: 10.3791/3037

Le-Niculescu, H., Levey, D. F., Ayalew, M., Palmer, L., Gavrin, L. M., Jain, N., et al. (2013). Discovery and validation of blood biomarkers for suicidality. Mol. Psychiatry 18, 1249-1264. doi: 10.1038/mp.2013.95

Mallory, A. C., and Vaucheret, H. (2006). Functions of microRNAs and related small RNAs in plants. Nat. Genet. 38(Suppl.), S31-S36. doi: 10.1038/ng0706$850 \mathrm{~b}$

Matthews, S. G., and Phillips, D. I. (2012). Transgenerational inheritance of stress pathology. Exp. Neurol. 233, 95-101. doi: 10.1016/j.expneurol.2011.01.009

Mattick, J. S., and Mehler, M. F. (2008). RNA editing, DNA recoding and the evolution of human cognition. Trends Neurosci. 31, 227-233. doi: 10.1016/j.tins.2008.02.003

Momeni, N., Bergquist, J., Brudin, L., Behnia, F., Sivberg, B., Joghataei, M. T., et al. (2012). A novel blood-based biomarker for detection of autism spectrum disorders. Transl. Psychiatry 2, e91. doi: 10.1038/tp.2012.19

Muralidharan-Chari, V., Clancy, J. W., Sedgwick, A., and D'Souza-Schorey, C. (2010). Microvesicles: mediators of extracellular communication during cancer progression. J. Cell Sci. 123, 1603-1611. doi: $10.1242 /$ jcs. 064386

Neale, B. M., Kou, Y., Liu, L., Ma’ayan, A., Samocha, K. E., Sabo, A., et al. (2012). Patterns and rates of exonic de novo mutations in autism spectrum disorders. Nature 485, 242-245. doi: 10.1038/nature11011

Noor, A., Whibley, A., Marshall, C. R., Gianakopoulos, P. J., Piton, A., Carson, A. R., et al. (2010) Disruption at the PTCHD1 Locus on Xp22.11 in Autism spectrum disorder and intellectual disability. Sci. Transl. Med. 2, 49ra68. doi: 10.1126/scitranslmed.3001267

O'Roak, B. J., Vives, L., Fu, W., Egertson, J. D., Stanaway, I. B., Phelps, I. G., et al. (2012a). Multiplex targeted sequencing identifies recurrently mutated genes in autism spectrum disorders. Science 338, 1619-1622. doi: 10.1126/science. 1227764

O’Roak, B. J., Vives, L., Girirajan, S., Karakoc, E., Krumm, N., Coe, B. P., et al. (2012b). Sporadic autism exomes reveal a highly interconnected protein network of de novo mutations. Nature 485 , 246-250. doi: 10.1038/nature10989

Qureshi, I. A., and Mehler, M. F. (2012). Emerging roles of non-coding RNAs in brain evolution, development, plasticity and disease. Nat. Rev. Neurosci. 13, 528-541. doi: 10.1038/nrn3234

Rajasethupathy, P., Antonov, I., Sheridan, R., Frey, S., Sander, C., Tuschl, T., et al. (2012). A role for neuronal piRNAs in the epigenetic control of memoryrelated synaptic plasticity. Cell 149, 693-707. doi: 10.1016/j.cell.2012.02.057

Rassoulzadegan, M., Grandjean, V., Gounon, P., Vincent, S., Gillot, I., and Cuzin, F. (2006). RNAmediated non-mendelian inheritance of an epigenetic change in the mouse. Nature 441, 469-474. doi: 10.1038/nature 04674

Ratajczak, J., Wysoczynski, M., Hayek, F., JanowskaWieczorek, A., and Ratajczak, M. Z. (2006). Membrane-derived microvesicles: important and underappreciated mediators of cell-to-cell communication. Leukemia 20, 1487-1495. doi: 10.1038/sj.leu.2404296

Rauch, A., Wieczorek, D., Graf, E., Wieland, T., Endele, S., Schwarzmayr, T., et al. (2012). Range of genetic mutations associated with severe nonsyndromic sporadic intellectual disability: an exome sequencing study. Lancet 380, 1674-1682. doi: 10.1016/S0140-6736(12)61480-9

Rechavi, O., Minevich, G., and Hobert, O. (2011) Transgenerational inheritance of an acquired small RNA-based antiviral response in $\mathrm{C}$. elegans. Cell 147, 1248-1256. doi: 10.1016/j.cell.2011.10.042

Rees, E., Kirov, G., O’Donovan, M. C., and Owen, M. J. (2012). De novo mutation in schizophrenia. Schizophr. Bull. 38, 377-381. doi: $10.1093 / \mathrm{schbul} / \mathrm{sbs} 047$

Saavedra-Rodriguez, L., and Feig, L. A. (2013). Chronic social instability induces anxiety and defective social interactions across generations. Biol. Psychiatry 73, 44-53. doi: 10.1016/j.biopsych.2012.06.035

Sanders, S. J., Ercan-Sencicek, A. G., Hus, V., Luo, R., Murtha, M. T., Moreno-De-Luca, D., et al (2011). Multiple recurrent de novo CNVs, including duplications of the 7q11.23 Williams syndrome region, are strongly associated with autism. Neuron 70, 863-885. doi: 10.1016/j.neuron.2011. 05.002

Saxe, J. P., and Lin, H. (2011). Small non-coding RNAs in the germline. Cold Spring Harb. Perspect. Biol. 3 , a002717. doi: 10.1101/cshperspect.a002717
Schwarz, E., Guest, P. C., Steiner, J., Bogerts, B., and Bahn, S. (2012). Identification of blood-based molecular signatures for prediction of response and relapse in schizophrenia patients. Transl. Psychiatry 2, e82. doi: 10.1038/tp. 2012.3

Smith, H. C., Bennett, R. P., Kizilyer, A., McDougall, W. M., and Prohaska, K. M. (2012). Functions and regulation of the APOBEC family of proteins. Semin. Cell Dev. Biol. 23, 258-268. doi: 10.1016/j.semcdb.2011.10.004

Sunkar, R., and Zhu, J. K. (2004). Novel and stress-regulated microRNAs and other small RNAs from Arabidopsis. Plant Cell 16, 2001-2019. doi: $10.1105 /$ tpc. 104.022830

Taft, R. J., Pheasant, M., and Mattick, J. S. (2007). The relationship between non-protein-coding DNA and eukaryotic complexity. Bioessays 29, 288-299. doi: 10.1002/bies.20544

Thery, C., Zitvogel, L., and Amigorena, S. (2002). Exosomes: composition, biogenesis, and function. Nat. Rev. Immunol. 2, 569-579. doi: 10.1038/nri855

Vallender, E. J., Mekel-Bobrov, N., and Lahn, B. T. (2008). Genetic basis of human brain evolution. Trends Neurosci. 31, 637-644. doi 10.1016/j.tins.2008.08.010

van der Pol, E., Boing, A. N., Harrison, P., Sturk, A., and Nieuwland, R. (2012). Classification, functions, and clinical relevance of extracellular vesicles. Pharmacol. Rev. 64, 676-705. doi: 10.1124/pr.112.005983

Vassoler, F. M., White, S. L., Schmidt, H. D., SadriVakili, G., and Pierce, R. C. (2013). Epigenetic inheritance of a cocaine-resistance phenotype. Nat. Neurosci. 16, 42-47. doi: 10.1038/ nn. 3280

Veltman, J. A., and Brunner, H. G. (2012). De novo mutations in human genetic disease. Nat. Rev. Genet. 13, 565-575. doi: 10.1038/nrg3241

Yoo, B. C., Kragler, F., Varkonyi-Gasic, E., Haywood, V., Archer-Evans, S., Lee, Y. M., et al. (2004). A systemic small RNA signaling system in plants. Plant Cell 16, 1979-2000. doi: 10.1105/tpc. 104.023614

Yu, T. W., Chahrour, M. H., Coulter, M. E., Jiralerspong, S., Okamura-Ikeda, K., Ataman, B., et al. (2013). Using whole-exome sequencing to identify inherited causes of autism. Neuron 77 , 259-273. doi: 10.1016/j.neuron.2012.11.002

Received: 25 April 2013; accepted: 05 November 2013; published online: 26 November 2013.

Citation: Barry $G$ (2013) Lamarckian evolution explains human brain evolution and psychiatric disorders. Front. Neurosci. 7:224. doi: 10.3389/fnins. 2013.00224

This article was submitted to Evolutionary Psychology and Neuroscience, a section of the journal Frontiers in Neuroscience.

Copyright (c) 2013 Barry. This is an open-access article distributed under the terms of the Creative Commons Attribution License (CC BY). The use, distribution or reproduction in other forums is permitted, provided the original author(s) or licensor are credited and that the original publication in this journal is cited, in accordance with accepted academic practice. No use, distribution or reproduction is permitted which does not comply with these terms. 